\title{
Effective Coping with Loneliness: A Review
}

\author{
Ami Rokach ${ }^{1,2}$ \\ ${ }^{1}$ York University, Toronto, Canada, \\ ${ }^{2}$ The Center for Academic Studies, Or Yehuda, Israel \\ Email: arokach@yorku.ca
}

How to cite this paper: Rokach, A. (2018). Effective Coping with Loneliness: A Review. Open Journal of Depression, 7, 61-72. https://doi.org/10.4236/ojd.2018.74005

Received: July 26, 2018

Accepted: November 27, 2018

Published: November 30, 2018

Copyright $\odot 2018$ by author and Scientific Research Publishing Inc. This work is licensed under the Creative Commons Attribution International License (CC BY 4.0).

http://creativecommons.org/licenses/by/4.0/

\begin{abstract}
Loneliness has been part of the human experience since the beginning of time. It cannot be avoided, but we may be able to cope with it, address its pain and possibly lower its frequency in our lives. This review addresses the theoretical approaches, and the author's own research which aims at exploring various means of coping with loneliness.
\end{abstract}

\section{Keywords}

Coping, Individual, Marital, Theoretical Approaches, Religion, Solitude

\section{Introduction}

Loneliness may, at last, start to come out of the closet. That's the encouraging news! As more research is available about the risks of loneliness to mental and physical health, more interventions to address chronic loneliness are being developed. "Coping is defined as individuals' constantly changing cognitive and behavioral efforts to manage specific external and internal demands appraised as taxing or exceeding their resources. It is essential to this definition that coping is process-oriented, i.e., coping efforts can change over time, and that coping is contextual, i.e., coping preferences differ in various contexts" (Schoenmakers et al., 2015: p. 154). The various coping strategies for loneliness include one-on-one interventions, such as mentoring or befriending (Dickens et al., 2011), group therapy with the lonely (Cacioppo et al., 2015; Masi, Chen, Hawkley, \& Cacioppo, 2010, for reviews). The authors report mixed results, with some approaches that simply do not yield the hoped-for results. The literature on strategies to reduce loneliness suggests that there are four major modalities: promoting and enhancing social support, improving social skills, increasing opportunities for social interaction and connectedness, and, challenging and changing maladaptive social cognitions (See de Jong Gierveld \& Fokkema, 2015). 
Research suggests that challenging and correcting maladaptive social cognition, are the most helpful for reducing loneliness (Masi, Chen, Hawkley, \& Cacioppo, 2011). Let's examine the various methods utilized to disseminate those coping strategies. "In order to more effectively intervene and reduce chronic loneliness, we must move beyond social opportunities and skills and develop a more comprehensive intervention framework that also facilitates the development of quality interpersonal relationships... the cognitive, emotional, and behavioral components contributing to loneliness are influenced by both working models and attachment. Thus, it is important to evaluate the attachment security and working models of a particular individual. By taking each of these elements into account, it increases the likelihood that a particular intervention will target the key components that lead to loneliness for that individual and significantly reduce his/her experience of loneliness..." (p. 249) maintained by DiTomasso Fizzel and Robinson (2015) and the author of this paper fully agrees with this assertion. To clarify, intervention programs must, in my opinion and experience, address the whole person meaning the manner in which he views himself, his ability to cope with problems and overcome obstacles, and his childhood experience with parents and significant others. These may not have been positive ones and as such could have negative effects on the person's life and functioning in his adulthood.

\section{This Author's Research on Coping with Loneliness}

Everyone has experienced loneliness at some point, and no one wants or likes it. Since loneliness is so painful, however, we would most commonly want to prevent it, or once we experience it, we want to find ways to lower the pain it causes and stop feeling alienated, isolated, and in turmoil. Although common to all people, loneliness is experienced differently by different people, and as such coping with it cannot be a unified strategy (Rokach, 1988, 1989; Rokach \& Sha'ked, 2013).

Rokach's research, which focused on the qualitative aspects of coping with loneliness, aimed at exploring how people feel about the efficacy of their coping strategies. In studying it it was discovered that the variety of effective coping strategies can be grouped into six dimensions.

Acceptance and Reflection, was the first dimension, and focused on using the opportunity of being by one's self and becoming aware of one's fears, wishes, and needs as the most salient means of coping with loneliness. This would appear to support Rook's (1984) suggestion that an inability to spend time alone may precipitate and/or exacerbate the experience of loneliness. Mate (2003) maintained that "Acceptance is simply the willingness to recognize and accept how things are. Acceptance does not demand becoming resigned to the continuation of whatever circumstances may trouble us, but it does require a refusal to deny exactly how things happen to be now... Acceptance implies a compassionate relationship with oneself" (p. 264). Those who will not allow awareness to 
guide them may attribute their pain to other reasons, and thus may be hampered when they attempt to deal with the pain of their loneliness.

The most salient coping strategy to emerge, Reflection and acceptance, indicates that one must have an encounter with one's self which involves a direct and straightforward facing of one's loneliness. As indicated by our study, such an encounter requires the willingness to experience fear, anger, agony, and/or disillusionment (Mayer Gaev, 1976; Moustakas, 1972). Andre (1991) maintained that finding relationships, friends, or partners may cure loneliness. Andre' believes that "only when we learn to live alone, and even to love alone-when we face our alienation, our vulnerability, our creativity, our uniqueness, our humanity, and our desires-will the problems of finding others and finding community become less urgent" (p. 19).

Solitude (i.e. welcomed aloneness) can aid in coping effectively with the pain of loneliness in that it stops our attempts to deny loneliness, thereby promoting its acceptance as an existential experience and at times, unavoidable. Solitude facilitates a greater understanding of ourselves, thereby learning to enjoy our own company, and taking the time and space to plan ways to overcome the conditions that precipitated the experience of loneliness. Only after loneliness has been accepted can coping be successful and beneficial experience of human existence. In accepting loneliness, the fear of its pain is no longer the driving force for coping. Instead, the individual becomes fully aware of himself as a human being by realizing his inner strength, resources, and ability to survive despite the anguish of loneliness (Moustakas, 1972). Consequently, the person is not desperate for intimate relationships; but can exert control over his life and become involved with others at will when he is ready to do so. Not clinging to a mate allows the person to gain more appreciation for human relations and thus be able to offer more of oneself to another.

Self-Development and Understanding, is the next dimension and it incorporates the increased self-intimacy and growth that often follow active participation in organized focus groups (i.e. Parents without Partners, Alcoholics Anonymous, dating clubs, etc.) and of receiving professional help or support and guidance from the clergy.

When we decide to consult a mental health professional, as a way of understanding our situation and struggles, we bring a new brand of connection into our lives-a connection with someone who can help us feel and function better. Therapy, as I have observed, can be quite helpful to the lonely. First and foremost, it can help the person to talk with another human being about important issues in her life and feel a relief. Another benefit is that it is possible for the person seeking therapy to share strong, painful emotions without needing to censor himself or worrying about the effect it may have on his relationship with the therapist. That alone may contribute to a feeling of belonging and a connection with another caring human.

Social Support Network, which we all need in order to survive, needs to be reestablished, or mended if it is not satisfactory. According to Baumeister and 
Leary (1995) four criteria can indicate whether people's lives are meaningful. They include 1) having a sense of purpose; 2) experiencing a sense of efficacy which is felt when we perceive that we have control over the outcomes; 3) when people realize that their actions have a positive value or are morally justified and 4) a sense of self-worth is essential for humans. Being satisfied by our social support system, seems to help us be generous, optimistic, and resilient. In turn, such a behavior will, most often elicit warmth and good-will from others and result in improving of our social network (Cacioppo \& Patrick, 2008). Sociability and a satisfying social support network were shown to be associated with greater resistance to developing colds when people were experimentally exposed to a cold virus (Cohen, Doyle, Turner, Alper, \& Skoner, 2003). Social support also buffered the effects of the psychological stress of depression, which people generally may be subjected to, for a short or long while. As Olds and Schwartz (2009) indicated "Although increased social participation may not ultimately offer lasting, deeply personal, and intimate relationships, such participation may provide company, a sense of belonging, and guidance and advice that one gets from acquaintances and friends. Framed by networks of kin and friends, participation in activities and hobbies, the enactment of social roles and the nature of social relationships is shaped and modified by experiences along the life course through the dynamic interaction of time and place" (p. 1).

Distancing and Denial, the fifth dimension of coping, confirms the connection found between loneliness and alcoholism, drug abuse, and other behavioral disorders or deviant behaviors (Rook, 1984). Feared stigma and loneliness anxiety, i.e. defending against the fear of experiencing loneliness (see Moustakas, 1972), may result in attempts to deny the experience either outright or by distancing oneself from the pain, feelings of failure, and restlessness and desperation that loneliness entails (Rook, 1988). Although previous writers (i.e. Moustakas, 1961, 1972; Rokach, 1990; Rokach \& Sha'ked, 2013) emphasized the need to face and accept loneliness as the initial step of coping with its pain successfully, it is interesting that Rokach's research indicated that denial may, indeed, be effective for a limited period. Denial and detachment may afford us some "space" or detachment from others in order to process and understand our situation and feel somehow protected while we are raw and in pain.

The Religion and Faith dimension, which I did not expect to find when I started my research, suggests that individuals need to feel connected to and/or worship a divine entity, God, or Supreme Being. Through affiliating with religious groups and practicing their faith, individuals gain strength, inner peace, and a sense of community and belonging.

Ritual is, apparently, an important source of solace for humans since it provides rewarding connections to the past and the future. Religion and faith may provide the person with connectedness to other worshippers, and thus increase her social circle, but also aid in providing solace that comes from feeling related to a protective and powerful supreme being (Andre, 1991). Azar (2010) sug- 
gested that religion has survived and thrived for more than 100,000 years, can be found in all cultures, with $85 \%$ of the world's population reporting that they belong or embrace some sort of religion or religious beliefs. Rituals that are practiced by each religious group have helped to unite the followers and encouraged them to live as a united entity to which they belong.

In their research, Dalton, Eberhardt, Bracken, and Echols (2006) reported that those who engage in spiritual quests may grow from them. Those who attain spiritual growth, are better able to accept the reality of their situation, they are successful at finding meaning in their trauma or stressful situation, they utilize creative coping strategies, and are reported to access their social support network more than others (Tedeschi \& Calhoun, 2004). It was found that spiritual struggles and quests, have led to profound personal growth, an increased ability to make meaning out of a situation and one's experience of loneliness, and engagement in positive problem solving actions (Pargament, 2007).

The distress of loneliness has also been described as "paralyzing hopelessness and unalterable futility" (Fromm-Reichman, 1959, in Rokach, 1988: p. 540). It is suggested that such a response to the pain and anxiety of loneliness is similar to the shock that one experiences following a traumatic event (Rokach, 1988). The Increased Activity dimension, the sixth one, appears to include strategies that counteract the immobilization associated with loneliness. Rather than be immersed in pain, helplessness, and sadness, lonely people may actively pursue not only their daily responsibilities but also leisure and fun-filled solitary or group activities as well, thus creating new opportunities for activity and social contact.

\section{Online Interventions for Loneliness}

Loneliness intervention programs seem to appear with increased frequency on the Internet (Seepersad, 2015). He suggested that lonely people have their loneliness amplified when they go online. And to counter it, Seepersad described some pertinent programs and the research which they generated. Stewart, Barnfather, Magill-Evans, Ray, and Letourneau (2011) conducted a study looking at online intervention with participants who had either cerebral palsy or spina bifid. The facilitators of those groups also had cerebral palsy or spina bifid. Significant decreases in loneliness as well as increases in social acceptance and confidence were consequently recorded. This intervention program seemed to reduce loneliness through an environmental approach by increasing opportunities for social contact. Another strategy used online involved the use of writing. van der Houwen, Schut, van den Bout, Stroebe, and Stroebe (2010), gave participants a writing intervention for bereaved individuals. Results demonstrated that there were decreased feelings of emotional loneliness and increase in positive mood compared to a control group.

Although no cognitively oriented programs to reduce loneliness are currently available on line, Seepersad (2015) maintained that it can be effective and should be developed. That, we need to remember, is a deviation from other approaches 
which basically aim at increasing opportunities for social contact, rather then also addressing maladaptive social cognition.

\section{Addressing Loneliness in Intimate Relationships}

Belonging is a basic human need. As is common in the Western society, the most important intimate adult bonding is marriage and intimate relationships (Laurenceau, Feldman, Barrett, \& Rovine, 2005). Research has repeatedly pointed out that an intimate relationship is essential to partners' physical and emotional well-being by fulfilling core psychological needs (i.e., love and intimacy, the need to be protected, cared for, and valued). A good and stable intimate or marital relationship which includes affection, love and support, is able to offer the couple a high degree of safety, and a deep sense of belonging, consequently making loneliness less likely (Strong, DeValut, \& Cohen, 2011). A bad marriage or intimate relationship might cause negative consequences to a person's psychological welfare (Baumeister \& Leary, 1995), including the painful feeling of exclusion and loneliness (Hendrick, 2004). If bad marriages are so harmful, we must know how to improve them. Some pointers for couples:

- Getting together for the right reasons. Sometimes, people get together and enter an intimate relationship not because they are a good fit, but mainly to avoid loneliness. When marriage is used as a solution to loneliness, the couple's loneliness is then the bond that keeps them together in an attempt to fend off loneliness (Rokach \& Sha'ked, 2013). A marriage that implants the fear of loneliness at its core, may unite two lonely people who will remain lonely throughout, and end up even lonelier when the relationship is over (see also Flora \& Segrin, 2000; Tornstam, 1992).

- Intimate sharing and involvement. the hallmark of intimate romantic relationships is the sharing of intimacy. Self-revealing to a partner who is supportive, can listen with interest and involvement, be non-judgemental, and accept the beloved partner even if his or her actions may not be condoned, are the cornerstones of a good and satisfying relationship (See also Prager \& Roberts, 2004; Reis et al., 2010). Relationships evolve, people change, and daily life's little problems all contribute to frustrations, anger and disappointments. If we are wise enough to address those difficulties, and not allow hard feelings to fester, the relationship will benefit, and become stronger. But if we allow the anger to become part of our makeup, it eventually comes between our partner and us. A gap filled with resentment, dissatisfaction and hostility can build leading to emptiness and loneliness.

- Mutual positive involvement. Mutual positive involvement fosters a safe environment where one feels cared for, listened to, and even rejuvenated, and helps the couple feel connected and united (see also Gable \& Reis, 2006).

- Interdependence: If we look for an optimal stage in a marriage or a relationship, it is situated between a high level of dependence and a high level of independence. Interdependence is the combination of independence and de- 
pendence [which if allowed to remain could be quite harmful to the union]. Being in a relationship because we need to, rather than because we want to, is deadly. Such a situation makes the couple either cling to one another without ever feeling secure in the other's love, or one clings while the other tries to flee and both are unhappy. In either case, they feel empty, lonely, and anxious (Schultz, 1976). Partners who are in an interdependent relationship realize and respect the understanding they are essentially two separate human beings-and not a reflection of each other. Two separate beings together in a relational unit (Rusbult, Bissonnett, Arriaga, \& Cox, 1998).

- Resolving relational conflicts. Relationships, and partners are not perfect. They are fraught with disagreements, and even fights (not physical, of course). These are normal, expected, and are sometimes helpful, as they provide an opportunity for the partners to vent what bothers, irritates, or concerns them. If not shared, the partners may experience loneliness and distance from one another (Hawkley \& Cacioppo, 2010). Personal skills and effective interpersonal patterns of interaction during conflict are essential to marital success, especially during the initial stage of marriage formation (Nichols, 1988).

- Benign neglect. McCarthy, Ginsberg, and Cintron (2008) observed that benign neglect is the couple's most "dangerous" enemy. In everyday language we may refer to it as taking-for-granted. Pre-emptive relational enhancing interactions are those couple interactions that help improve the relationship by preventing or minimizing that taking the partner as a given, and not paying much attention to relational dynamics (see also Amato, Booth, Johnson, \& Rogers, 2007).

- Avoiding bidirectional growth: Therapists are sometimes confronted with a partner exclaiming "look at us; we were so close and alike when we started our relationships years ago, and now we hardly know each other". People are commonly mystified by their inability to connect with their long-term partner with whom they connected very well in the beginning of their relationship. In treating troubled couples, the author understood that the reason for such a phenomenon is what the present author termed bidirectional growth; each partner grows or does not grow to a different direction and sometimes in a different speed. One of the best ways to prevent distancing and loneliness in romantic relationships is to grow together. When only one partner develops and grows, he or she then experiences the world differently and consequently mentally or emotionally live in a different world than his or her partner. This can be prevented by enhancing one's partner's personal growth is a sign of a respectful and nourishing relationship. When the two partners grow and change at a similar pace and in a similar trajectory (i.e., he attends cooking classes and she a book club), then the relational equilibrium is maintained. However, if only one member of the couple undergoes personal development and growth, it may alienate them from one another since they will have less common topics to discuss, their interests may change, and so 
will their outlook on themselves and on life. Such a relationship does not have a high chance to survive, and if it does, it will most probably become an empty shell.

- Overcoming the scarring of the long-lasting marital distress that erodes relational resources and leaves partners with fewer and weaker buffers to deal with problems and to protect against inevitable future conflicts.

- Seeking help before it is too late: Seeing couples for the past 40 years, I have noticed that most couples seek therapy when the situation between them is seriously harmed (Gottman \& Gottman, 1999). Seeking help when problems first start is a much better and safer strategy that may succeed in not only saving the marriage, but intimacy and love as well.

\section{How Can Therapy Help?}

Being in the helping profession, the readers may wonder how can therapy assist the lonely. Beck and Malley (1998) commented that a sense of feeling disconnected is responsible for the alienation, apathy and a sense of emptiness that today's youth experience, and which contribute to drug and alcohol abuse, rising violence, depression, and suicide. And despite all that, we find that psychological theory and practice appear to not see the importance of belonging to a healthy and productive functioning. Friedman (2007) pointed out that "viewing sense of belonging as a framework through which to examine a client's life inherently links the individual with the community that defines and supports her, and invites a dialogue illuminating the fundamental relationship between the two" (p. 77).

The client may start to feel connected and experience a sense of belonging in the therapy room. The question is how can therapists help reverse the self orientation of contemporary life by integrating a sense of community into clients' vision and life. The obvious way is by encouraging clients to actively seek to become part of a larger community. Friedman (2007) provides the experience afforded the client in narrative therapy as an example of what therapists can do to help open up the client to the community. In narrative therapy the client is invited to re author his life in a manner that is more suitable for her, and "audiences" may be invited to share those re authored stories. Such audiences, may play a key role in helping the client, since these "audiences of concern" which provide new lenses through which to interpret experiences while supporting the client all along (Morgan, 2000).

Since in-office counseling may not be sufficient to help the lonely, or not attractive enough for them to attend, the inclusion of animal-assisted therapy (AAT) is gaining momentum on college campuses nationwide (Stewart, Chang, \& Rice, 2013). AAT in counseling is defined as the incorporation of specially trained and evaluated pets as therapeutic agents into the counseling process; thus, counselors utilize the human-animal bond in goal-directed interventions as part of the treatment process. Research exploring the effectiveness of AAT indi- 
cated that it may facilitate the therapeutic alliance between counselor and client, and encourages non-threatening interactions between them (Stewart, Chang, \& Rice, 2013). Additionally, the presence of specially trained animals as part of therapy, encourages client relaxation (Barker, Knisely, McCain, Schubert, \& Pandurangi, 2010). A quote from Ornish's (1998) book will close this review, where he discussed what a strong and overwhelming need for belonging may cause a person to do. "When people are unable to experience the feeling of connection and community in healing ways, they will often find it in ways that are dark and destructive... Joining a gang is becoming a popular way of getting a sense of community and family, even if you have to rob or to kill somebody to join the gang... In San Diego, thirty nine people chose to commit suicide together in 1997, many of whom already had undergone surgical castration in order to be part of that community" (p. 19). And all that, in order to be part of a community, what are we then, as researchers, educators, and communities to do? "As a first step" contend Cacioppo et al. (2015) "there is a need for increased public awareness-and awareness among healthcare providers-that loneliness is a condition that, like chronic pain, can become an affliction for almost anyone. Even popular and high-status individuals can find themselves feeling lonely, and the stigma of loneliness further complicates assessment and treatment. Despite the fact that loneliness is a common emotional distress syndrome with a high-risk factor for early mortality and a broad variety of physical health and psychiatric issues, it still gets little attention in medical training or in healthcare more generally" (p. 245).

\section{Conflicts of Interest}

The authors declare no conflicts of interest regarding the publication of this paper.

\section{References}

Amato, P. R., Booth, A., Johnson, D. R., \& Rogers, S. J. (2007). Alone Together: How Marriage in America Is Changing. Cambridge, MA: Harvard University Press.

Andre, R. (1991). Positive Solitude: A Practical Program for Mastering Loneliness and Achieving Self-Fulfillment. NY: Harper Collins.

Azar, B. (2010). A Reason to Believe. Montior on Psychology, 41, 52-56.

Barker, S. B., Knisely, J. S., McCain, N. L., Schubert, C. M., \& Pandurangi, A. K. (2010). Exploratory.

Baumeister, R. F., \& Leary, M. R. (1995). The Need to Belong: Desire for Interpersonal Attachments as a Fundamental Human Motivation. Psychological Bulletin, 117, 497-529. https://doi.org/10.1037/0033-2909.117.3.497

Beck, M., \& Malley, J. (1998). A Pedagogy of Belonging. Reclaiming Children and Youth, 7, 133-137.

Cacioppo, J. T. \& Patrick, W. (2008). Loneliness: Human Nature and the Need for Social Connection. New York: W.W. Norton.

Cacioppo, S., Grippo, A. J., London, S., Goossens, L., \& Cacioppo, J. T. (2015). Loneliness: Clinical Import and Interventions. Perspectives on Psychological Science, 10, 238-249. 
https://doi.org/10.1177/1745691615570616

Cohen, S., Doyle, W. J., Turner, R. B., Alper, C. M., \& Skoner, D. P. (2003). Sociability and Susceptibility to Thecommon Cold. Psychological Science, 14, 389-395. https://doi.org/10.1111/1467-9280.01452

Dalton, J. C., Eberhardt, D., Bracken, J. \& Echols, K. (2006). Inward Journeys: Forms and Patterns of College Student Spirituality. Journal of College and Character, 7, 1-22. https://doi.org/10.2202/1940-1639.1219

De Jong Gierveld, J., \& Fokkema, T. (2015). Strategies to Prevent Loneliness. In Sha'ked A., \& Rokach A. (Eds.), Addressing Loneliness: Coping, Prevention and Clinical Interventions. NY: Routledge.

Dickens, A. P., Richards, S. H., Hawton, A., Taylor, R. S., Greaves, C. J., Green, C., Campbell, J. L., et al. (2011). An Evaluation of the Effectiveness of a Community Mentoring Service for Socially Isolated Older People: A Controlled Trial. BMC Public Health, 11, 218. http://www.biomedcentral.com/1471-2458/11/218 https://doi.org/10.1186/1471-2458-11-218

DiTomasso, E., Fizzel, S. R., \& Robinson, B. A. (2015). Chronic Loneliness within an Attachment Framework: Process and Interventions. In Sha'ked A. \& Rokach A. (Eds.) Addressing Loneliness: Coping, Prevention and Clinical Interventions. NY: Routledge.

Flora, J., \& Segrin, C. (2000). Relationship Development in Dating Couples: Implications for Relational Satisfaction and Loneliness. Journal of Social and Personal Relationships, 17, 811-825. https://doi.org/10.1177/0265407500176006

Friedman, R. L. (2007). Widening the Therapeutic Lens: Sense of Belonging as an Integral Dimension of the Human Experience. A Dissertation Submitted to the Wright Institute Graduate School.

Fromm-Reichman, F. (1959). Loneliness. Psychiatry, 22, 1-5. https://doi.org/10.1080/00332747.1959.11023153

Gable, S. L., \& Reis, H. T. (2006). Intimacy and the Self: An Interactive Model of Self and Close Relationships. In P. Noller, \& J. A. Feeney (Eds.), Close Relationships: Functions, Forms and Processes (pp. 211-225). New York: Psychology Press.

Gottman, J. M., \& Gottman, J. S. (1999). The Marriage Survival Kit: A Research-Based Marital Therapy. In R. Berger, \& M. T. Hannah (Eds.), Preventive Approaches in Couples Therapy (pp. 304-330). New York: Routledge.

Hawkley, L. C., \& Cacioppo, J. T. (2010). Loneliness Matters: A Theoretical and Empirical Review of Consequences and Mechanisms. Annals of Behavioral Medicine, 40, 218-227. https://doi.org/10.1007/s12160-010-9210-8

Hendrick, S. S. (2004). Understanding Close Relationships. New York: Pearson.

Laurenceau, J. P., Feldman Barrett, L., \& Rovine, M. J. (2005). The Interpersonal Process Model of Intimacy in Marriage: A Daily-Diary and Multilevel Modeling Approach. Journal of Family Psychology, 19, 314-323. https://doi.org/10.1037/0893-3200.19.2.314

Masi, C. M., Chen, H.-Y., Hawkley, L. C., \& Cacioppo, J. T. (2010). A Meta-Analysis of Interventions to Reduce Loneliness. Personality and Social Psychology Review, 15, $1-48$.

Masi, C. M., Hsi-Yuan, C., Hawkley, L. C., \& Cacioppo, J. T. (2011). A Meta-Analysis of Interventions to Reduce Loneliness. Personality and Social Psychology Review, 15, 219-266. https://doi.org/10.1177/1088868310377394

Mate, G. (2003). When the Body Says No: The Cost of Hidden Stress. Toronto: Vintage.

Mayer Gaev, D. (1976). The Psychology of Loneliness. Chicago, IL: Adams. 
McCarthy, B., Ginsberg, R. L., \& Cintron, J. A. (2008). Primary Prevention the First Two Years of Marriage. Journal of Family Psychotherapy, 19, 143-156. https://doi.org/10.1080/08975350801904940

Morgan, A. (2000). What Is Narrative Therapy. http://dulwichcentre.com/au/alicearticle.htm

Moustakas, C. E. (1961). Loneliness. Engelwood Cliffs, NJ: Prentice Hall.

Moustakas, C. E. (1972). Loneliness and Love. Englewood Cliffs, NJ: Prentice-Hall.

Nichols, W. C. (1988). Marital Therapy: An Integrative Approach. New York: The Guilford Press.

Olds, J., \& Schwartz, R. S. (2009). The Lonely American: Drifting Apart in the Twenty-First Century. Boston, MA: Beacon Press.

Ornish, D. (1998). Love and Survival: The Scientific Basis for the Healing Power of Intimacy. New York: HarperCollins.

Pargament, K. J. (2007). Spirituality Integrated Therapy: Understanding and Addressing the Sacred. New York: Guilford Press.

Prager, K. J., \& Roberts, L. J. (2004). Deep Intimate Connection: Self and Intimacy in Couple Relationships. Mahwah, NJ: Lawrence Erlbaum Associates Publishers.

Reis, H. T., Smith, S. M., Tsai, F. F., Carmichael, C. L., Caprarielle, P. A., Rodrigues, A., \& Maniaci, M. R. (2010). Are You Happy for Me? How Sharing Positive Events with Others Provide Personal and Interpersonal Benefits. Journal of Personality and Social Psychology, 99, 311-329. https://doi.org/10.1037/a0018344

Rokach, A. (1988). Theoretical Approaches to Loneliness: From a Univariate to a Multidimensional Experience. Review of Existential Psychology and Psychiatry, 19, 225-254.

Rokach, A. (1989). Antecedents of Loneliness: A Factorial Analysis. Journal of Psychology, 123, 369-384. https://doi.org/10.1080/00223980.1989.10542992

Rokach, A. (1990). Surviving and Coping with Loneliness. The Journal of Psychology, 124, 39-54. https://doi.org/10.1080/00223980.1990.10543204

Rokach, A., \& Sha'ked, A. (2013). Together and Lonely: Loneliness in Intimate Relationships-Causes and Coping. New York: Nova Pub.

Rook, K. S. (1984). Promoting Social Bonding: Strategies for Helping the Lonely and Socially Isolated. American Psychologist, 39, 1389-1407.

https://doi.org/10.1037/0003-066X.39.12.1389

Rusbult, C. E., Bissonnette, V. L., Arriage, X. B., \& Cox, C. L. (1998). Accommodation Process during the Early Years of Marriage. In T. N. Bradbury (Ed.), The Developmental Course of Marital Dysfunction (pp. 74-113). Cambridge: Cambridge University Press.

Schoenmakers, E. C., van Tilburg, T. G., \& Fokkema, T. (2015). Problem-Focused and Emotion-Focused Coping Options and Loneliness: How Are They Related? European Journal of Ageing, 12, 153-161.

Schultz, T. (1976). Bittersweet: Surviving and Growing from Loneliness. New York: T. Crowell.

Seepersad, S. S. (2015). Helping the "Poor Get Richer"-Successful Internet Loneliness Intervention Programs. In A. Sha'ked, \& A. Rokach (Eds.), Addressing Loneliness: Coping, Prevention and Clinical Interventions (pp. 231-240, Vol. 1). New York: Routledge.

Stewart, L., Chang, C., \& Rice, R. (2013). Emergent Theory and Model of Practice in Animal-Assisted Therapy in Counseling. Journal of Creativity in Mental Health, 8, 
329-348. https://doi.org/10.1080/15401383.2013.844657

Stewart, M., Barnfather, A., Magill-Evans, J., Ray, L., \& Letourneau, N. (2011). Brief Report: An Online Support Intervention: Perceptions of Adolescents with Physical Disabilities. Journal of Adolescence, 34, 795-800.

https://doi.org/10.1016/j.adolescence.2010.04.007

Strong, B., DeValut, C., \& Cohen, T. F. (2011). The Marriage and Family Experience: Intimate Relationships in a Changing Society(11th ed.). Belmont, CA: Wadsworth.

Tedeschi, R. G., \& Calhoun, L. G. (2004). Posttraumatic Growth: Conceptual Foundations and Empirical Evidence. Psychological Inquiry, 15, 1-18.

https://doi.org/10.1207/s15327965pli1501_01

Tornstam, L. (1992). Loneliness in Marriage. Journal of Social and Personal Relationships, 9, 197-217. https://doi.org/10.1177/0265407592092003

van der Houwen, K., Schut, H., van den Bout, J., Stroebe, M., \& Stroebe, W. (2010). The Efficacy of a Brief Internet-Based Self-Help Intervention for the Bereaved. Behaviour Research and Therapy, 48, 359-367. https://doi.org/10.1016/j.brat.2009.12.009 